\title{
review
}

\section{Carcinogenesis induced by low-dose radiation}

\author{
Igor Piotrowski1, Katarzyna Kulcenty ${ }^{1,2}$, Wiktoria Maria Suchorska1,2, Agnieszka Skrobała',3, \\ Matgorzata Skórska³, Marta Kruszyna-Mochalska²,3, Anna Kowalik³, Weronika Jackowiak, \\ Julian Malicki²,3
}

\author{
${ }^{1}$ Radiobiology Laboratory, Department of Medical Physics, Greater Poland Cancer Centre, Poznań, Poland \\ ${ }^{2}$ Department of Electroradiology, University of Medical Sciences, Poznań, Poland \\ ${ }^{3}$ Department of Medical Physics, Greater Poland Cancer Centre, Poznań, Poland \\ ${ }^{4}$ Radiotherapy Ward I, Greater Poland Cancer Centre, Poznań, Poland
}

Radiol Oncol 2017; 51(4): 369-377.

Received 4 July 2017

Accepted 25 September 2017

Correspondence to: Dr. Katarzyna Kulcenty, Radiobiology Laboratory, Department of Medical Physics, Greater Poland Cancer Centre, Garbary 15 Street, Poznań, Poland. E-mail: katarzyna.kulcenty@wco.pl

Igor Piotrowski and Katarzyna Kulcenty contributed equally to this work.

Disclosure: No potential conflicts of interest were disclosed.

Background. Although the effects of high dose radiation on human cells and tissues are relatively well defined, there is no consensus regarding the effects of low and very low radiation doses on the organism. Ionizing radiation has been shown to induce gene mutations and chromosome aberrations which are known to be involved in the process of carcinogenesis. The induction of secondary cancers is a challenging long-term side effect in oncologic patients treated with radiation. Medical sources of radiation like intensity modulated radiotherapy used in cancer treatment and computed tomography used in diagnostics, deliver very low doses of radiation to large volumes of healthy tissue, which might contribute to increased cancer rates in long surviving patients and in the general population. Research shows that because of the phenomena characteristic for low dose radiation the risk of cancer induction from exposure of healthy tissues to low dose radiation can be greater than the risk calculated from linear no-threshold model. Epidemiological data collected from radiation workers and atomic bomb survivors confirms that exposure to low dose radiation can contribute to increased cancer risk and also that the risk might correlate with the age at exposure.

Conclusions. Understanding the molecular mechanisms of response to low dose radiation is crucial for the proper evaluation of risks and benefits that stem from these exposures and should be considered in the radiotherapy treatment planning and in determining the allowed occupational exposures.

Key words: low-dose radiation; carcinogenesis; DNA; radiation induced bystander effect

\section{Introduction}

Ionizing radiation is widely used in medical procedures, including cancer radiotherapy and the use in diagnosis. ${ }^{1}$ For over a century the biological effects of medium- and high-dose radiation (over $0.5 \mathrm{~Gy}$ ) on human health have been investigated. Induction of cancer is one of the most severe longterm effects of radiotherapy. While the relationship between radiation effects and dose is well defined at higher doses, the effects of doses below 0.5 Gy are still unclear. Even though the use of radiotherapy resulted in a significant increase in cancer survivors ${ }^{2}$, it is important to investigate the potential negative long-term effects of radiation, considering that further advancements in therapy result in increased length of patients life after therapy. Table 1 presents the classification of radiation doses according to Kadhim et al. ${ }^{3}$ paired with examples of exposures.

The damage to DNA is induced by radiation through two mechanisms: the direct and indirect effect. ${ }^{9}$ Directly induced damage results from the deposition of radiation energy in the DNA molecule creating a break. Damage induced indirectly is a result of an attack of the reactive species, which might be produced from ionization of water, on DNA molecule. These processes induced by radia- 
TABLE 1. Dose ranges and sources of radiation exposure

\begin{tabular}{|c|c|c|}
\hline & Dose range & Examples of exposure \\
\hline Very low doses & $<0.05 \mathrm{~Gy}$ & Mammography ${ }^{4}$, chest X-ray ${ }^{4}$ \\
\hline Low doses & $0.05-0.5$ Gy & Cardaic CT angiogram ${ }^{4}$ \\
\hline Medium doses & $0.5-5$ Gy & $\begin{array}{l}\text { One fraction dose in standard fractionated } \\
\text { radiotherapy }{ }^{5} \text {, dose absorbed by workers } \\
\text { during Fukushima accident }{ }^{6}\end{array}$ \\
\hline High doses & 5-15 Gy & Intraoperative radiotherapy (as boost) \\
\hline Very high doses & $>15 \mathrm{~Gy}$ & $\begin{array}{l}\text { Intraoperative radiotherapy8 }{ }^{8} \text { cumulative } \\
\text { dose delivered during fractionated } \\
\text { radiotherapy }\end{array}$ \\
\hline
\end{tabular}

tion result in creation of single-strand breaks (SSB) and double-strand breaks (DSB) in DNA molecule. ${ }^{10}$ DSBs are prime lesions induced by ionizing radiation, and are responsible for its deleterious effect. Densely ionizing radiation has the ability to induce more damage per cell, making it possible for two or more lesions to be induced in proximity. These groups of breaks are called clustered DNA lesions, and are harder to repair than single DSBs and SSBs. ${ }^{11}$ Density of radiation correlates with reparability of DNA lesions, with densely ionizing radiation being harder to repair. Radiation stimulates DNA damage repair through non-homologous end-joining $(\mathrm{NEHJ})^{12}$, an error prone pathway that can lead to induction of chromosome aberrations, which in turn may cause genomic instability. ${ }^{13}$ Genomic instability has been connected to induction of most of the human cancers, however currently the exact mechanism of radiationinduced carcinogenesis is not clear.

The dose-rate of radiation plays a major role in how much damage an exposed cell receives. High

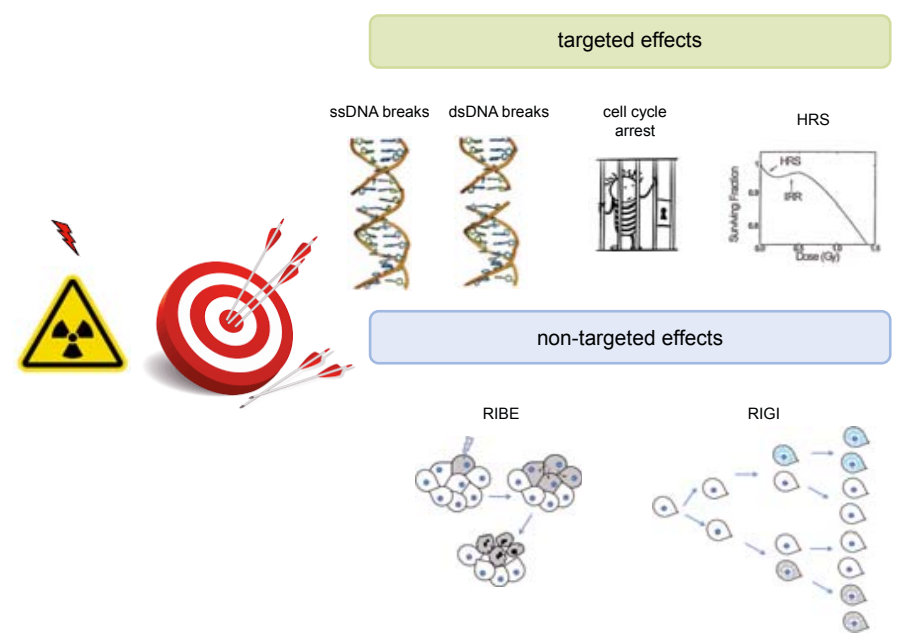

FIGURE 1. Diagram illustrating targeted and non-targeted effect induced by radiation (all described in the main text). dose-rate irradiation, like radiation created by atomic bomb, results in deployment of energy in very short time to every irradiated cell. However if radiation is protracted over long periods of time, like the dose-rates considered in calculations of occupational and environmental radiation risks, the cell turnover influences how many 'hits' a cell will receive. Low-dose rates also influence how cell reacts regarding the repair of DNA damage, since low-dose rates allow more time for damage to be repaired which makes it more favorable for cells than high-dose rate radiation. ${ }^{14}$

This review contains a description of biological consequences of low-dose radiation and possible induction of cancer (Figure 1).

\section{DNA damage}

Damage to DNA is one of the most important factors in radiation induced cancer transformation. Even though ionizing radiation induces one DSB per 20 SSBs, research indicates that DSBs are much more impactful effect of irradiation (IR). ${ }^{15}$ This difference might be caused by the fact that SSBs are repaired by error-free mechanisms and are not sustained, while DSBs induced by radiation are repaired by mechanisms prone to mis-repair and repair failure, making DSBs a main cause of radiation induced cell death. ${ }^{16}$ Recently many authors pointed towards important differences between DNA damage response exerted by high and low doses of radiation. ${ }^{17,18}$ Research of low dose effect on normal tissues is especially significant considering side effects of radiotherapy treatment.

Induction of DSBs is considered to be one of the main mechanisms by which radiation exerts its deleterious effect. One of the earliest events appearing in response to DSB induction is phosphorylation of histone H2AX by protein kinases: DNA-dependent protein kinase catalytic subunit (DNA-PKCs), ataxia telangiectasia and Rad3related (ATR) and ataxia telangiectasia mutated (ATM) ${ }^{19}$ Phosphorylated H2AX ( $\gamma \mathrm{H} 2 \mathrm{AX}$ ) foci appears around the DNA break as a part of DSB repair mechanism ${ }^{20}$ and it corresponds directly with the number of DSBs. ${ }^{21}$ The correlation between the radiation dose and the initial number of $\gamma \mathrm{H} 2 \mathrm{AX}$ foci it induces has already been thoroughly described. ${ }^{21,22}$ Rothkamm et al. ${ }^{23}$ have shown that this linear correlation holds true also for the X-ray doses as low as $1 \mathrm{mGy}$ (at dose rate of 6-60 mGy/ $\mathrm{min}$ ) for nondividing human fibroblasts cultured in vitro. Interestingly, authors came to the conclu- 


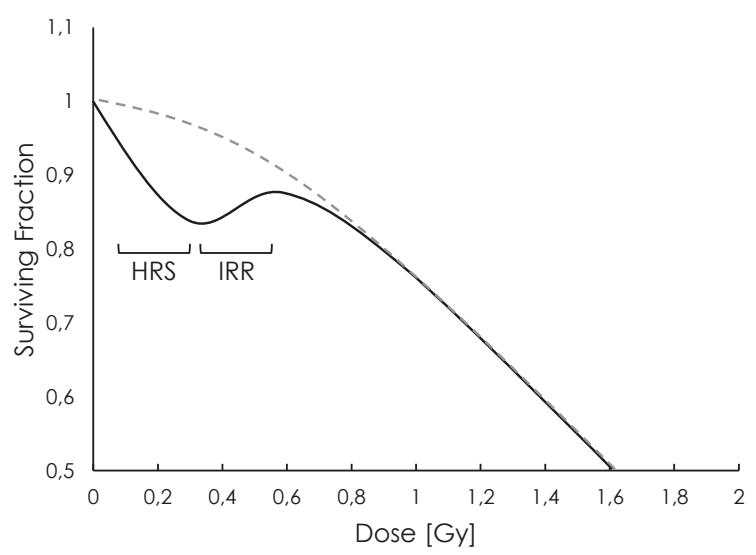

FIGURE 2. Schematic diagram illustrating cell survival curve for cells exhibiting low dose hyper radiosensitivity (HRS). Solid line shows survival curve with evidence of HRS and increased radioresistance (IRR). Dashed line shows survival curve with no evidence of HRS and IRR. Image adapted from. ${ }^{29}$

sion that the damage induced by these very low doses remains unrepaired and evidence suggests that the cells with unrepaired DSBs are eliminated. Similar results were observed recently by Osipov et al. in research conducted on human MSCs isolated from oral mucosa. ${ }^{24}$ Authors measured kinetics of $\gamma \mathrm{H} 2 \mathrm{AX}$ and $\mathrm{pATM}$ foci formation after irradiation with $\mathrm{X}$-rays at doses ranging from $20 \mathrm{mGy}$ to 250 $\mathrm{mGy}$ and a dose rate of $40 \mathrm{mGy} / \mathrm{min}$. Linear correlation between the number of $\gamma \mathrm{H} 2 \mathrm{AX}$ foci and radiation dose was observed at all time-points after irradiation. For the intermediate doses (160 and $250 \mathrm{mGy}$ ) the highest number of foci was observed at $60 \mathrm{~min}$ followed by a significant decrease, which is typical for $\gamma \mathrm{H} 2 \mathrm{AX}$ kinetics observed at higher doses. However for the lower doses (20, 40 and 80 $\mathrm{mGy}$ ) after initial rise in $\gamma \mathrm{H} 2 \mathrm{AX}$ foci number no decrease was observed. Considering the fact that pATM foci did not co-localize with $\gamma \mathrm{H} 2 \mathrm{AX}$ foci at low doses and the fact that low dose radiation stimulates the MSC proliferation ${ }^{25}$, authors propose that the persistence of $\gamma \mathrm{H} 2 \mathrm{AX}$ foci after irradiation with low dose $X$-rays might be a consequence of new DSBs appearing as a result of replication stress rather than resulting from inefficient repair of DSBs. It is important to note that doses used in these experiments are in range of doses used in diagnostic procedures like CT scan. ${ }^{26}$ However high linear energy transfer (LET) radiation has also been shown to induce ATM-dependent responses at low doses. ${ }^{27}$ Fibroblasts isolated from patients with ataxia telangiectasia and healthy persons were irradiated with carbon ion beams $(\mathrm{LET}=70 \mathrm{keV} / \mu \mathrm{m})$ or with X-rays at doses between 0.1 to $2 \mathrm{~Gy}$. Results have shown that mutation frequency and cell survival after low dose carbon ion irradiation were dependent on ATM status. Authors also compared the number of $\gamma \mathrm{H} 2 \mathrm{AX}$ foci in cells with different activity of ATM irradiated with 0.2 Gy of carbon ion radiation. Results indicate that ATM plays an important role in early DSB recognition and can be responsible for inefficient DSB repair, which is in line with conclusions reached by Osipov et al. ${ }^{24}$ Authors also observed that doses higher than 0.5 Gy of carbon ion radiation caused an early G2/M arrest dependent on ATM. Some authors suggest that occurrence of this arrest might support DNA DSB repair, while a failure to induce early G2 arrest can be one of the factors responsible for low dose hyper-radiosensitivity (HRS). ${ }^{28}$

\section{Low-dose hyper radiosensitivity (HRS)}

HRS is described as an increase in radiosensitivity in cells exposed to low-dose radiation, usually below $0.2-0.3$ Gy for low LET radiation. When cells are exposed to doses higher than 0.3 Gy an increase in radioresistance is observed and the transition towards it on dose response curve is described as increased radioresistance (IRR) ${ }^{29}$ Figure 2 presents the dose-response curves with and without the evidence of HRS and IRR. Occurrence of HRS and IRR in cells was first described using an in vitro culture of V79 Chinese hamster cells. ${ }^{30}$ Cells were exposed to $\mathrm{X}$-ray radiation doses ranging between 0.01 and $10 \mathrm{~Gy}$. Using clonogenic assay authors have shown increased effectiveness of X-ray doses below 0.2 Gy. Cells exposed to doses higher than 0.4 Gy experienced a rise in radioresistance. Authors hypothesized that only X-ray doses above certain threshold can induce enough damage to activate DNA damage repair mechanisms. The dependence of HRS occurrence on cell cycle phase was also firstly noted in this research. Since then, research of HRS on different cell lines reported that HRS is increased in G2-phase cells. ${ }^{31,32}$ To prove this concept Short et al. ${ }^{31}$ used two glioma cell lines - T98G exhibiting HRS and U373 that did not exhibit HRS. Using cell counting authors have shown that G2 population of T98G cells irradiated with low dose X-rays demonstrated more pronounced HRS than cells in asynchronous population. Interestingly the G2 population of U373 cells also exhibited HRS indicating that in the asynchronous population the response of G1 and S-phase cells dominates. These results show that actively proliferating cells might 
be more sensitive to low doses of radiation. It is important to note, that HRS can potentially be used to therapeutic advantage. Using ultra-fractionation with doses in HRS range it is possible to achieve more cytotoxic effects than after administration of same total dose at once. ${ }^{33}$

\section{Cell cycle arrest}

In order to repair the damaged DNA, irradiated cells utilize cell cycle arrest to allow sufficient time for the DNA repair. The most important checkpoint pathways that initiate the radiation-induced arrest inhibit the cell cycle progression from G2 phase to mitosis. Two checkpoints are utilized for the repair of DNA damage induced by radiation. The classic G2/M checkpoint is activated after high doses of radiation and its role is to arrest the cells damaged in S or G1 cell cycle phase. ${ }^{34}$ The early G2/M checkpoint is activated shortly after exposure to radiation and it exclusively protects cells in G2 phase of cell cycle from radiation effects. ${ }^{35}$ This checkpoint is especially relevant to assessment of low-dose radiation risks because induction of this checkpoint occurs after irradiation with doses up to 10 Gy of low LET radiation ${ }^{35}$ and a threshold for its activation is observed at radiation doses of $0.3 \mathrm{~Gy} .{ }^{36}$ This threshold dose coincides with radiation doses at which a transition between HRS and IRR is observed, suggesting a correlation between the two phenomenon, which was first suggested by Marples et al. ${ }^{36}$ The activation of early G2/M checkpoint is mediated by radiation-induced, DSBdependent phosphorylation of ATM. ${ }^{37}$ It has been hypothesized that ATM acts by an interplay with Chk1 and Chk2. ${ }^{32}$ Inhibition of these factors in fibroblast cells results in an enhanced HRS response, however it also causes an increase in IRR. It is important to note that the response varied depending on the HRS status of the cell lines used.

While even very low doses of radiation are capable of inducing DSBs, there is evidence suggesting a threshold number of 10-20 DSBs for the triggering of ATM dependent G2/M checkpoint. ${ }^{38}$ This can mean that low doses of radiation inducing few DSBs may not trigger G2/M arrest in irradiated cells, making it possible for cells with unrepaired DSBs to enter mitosis, which in turn might result in loss of genetic material. ${ }^{39}$ Deckbar et al. ${ }^{40}$ investigated induction of G2 arrest by X-ray radiation on immortalized fibroblasts and on primary human cells. $\gamma \mathrm{H} 2 \mathrm{AX}$ foci count confirms, that cells irradiated with $\mathrm{X}$-ray doses inducing fewer than $\sim 20$
DSBs (below 0.6 Gy for immortalized fibroblasts and below 0.2 Gy for primary human cells) did not enter G2 arrest. In cells irradiated with doses above the threshold dose, cells that exited the G2 checkpoint still had 20 unrepaired DSBs and 1-2 chromosome breaks. These results indicate that a certain threshold of DSBs and chromosome aberrations is necessary for both activating and maintaining the G2 checkpoint arrest. The threshold dose at which G2 arrest is induced can play a role in lowdose radiosensitivity of a cell. Different cell lines show variability in this threshold dose. Although this threshold usually varies between 0.2 Gy and $0.6 \mathrm{~Gy}$, in some cell lines the cell cycle arrest is induced without threshold. ${ }^{41}$ Currently the mechanism behind this difference in threshold dose is not known, however a hypothesis has been proposed stating that cell lines which show early G2 checkpoint after exposure to very low doses might have higher base level of DSBs, making it much easier to reach the number of DSBs needed for G2 arrest induction. ${ }^{41}$

Mutation in ATM gene observed in Ataxia telangiectasia, has been connected with increased chromosomal radiosensitivity and increased susceptibility to cancer. ${ }^{42}$ Since both DNA damage repair and G2 checkpoint induction depend on ATM kinase, Ataxia telangiectasia (AT) cells are often used to investigate the mechanisms of these processes. Using AT cells researchers were able to show for the first time that G2 checkpoint facilitates not only the repair of DSBs, but also the repair of chromosomal breaks, after irradiation with $1 \mathrm{~Gy}$ ionizing radiation. ${ }^{43}$ Failure to activate the G2 checkpoint might be one of the reasons for increased cancer rates in patients with Ataxia telangiectasia, since unrepaired damage to DNA might alter cells genome leading to malignant transformation. ${ }^{42}$

\section{Non-targeted effects}

\section{Radiation induced genomic instability (R|GI)}

Radiation induced DNA damage, specifically DSBs, are very important in occurrence of chromosomal instability, which may involve aneuploidy, deletions, and aberrations, which in turn might contribute to carcinogenesis. ${ }^{44}$ The non-targeted effects, including bystander effects and genomic instability, contribute to the induction of cancer in a less clear way. ${ }^{45}$ The progeny of exposed cell might exhibit phenotypes such as chromosomal aberrations and rearrangements, gene mutations and en- 
hanced cell death rate. ${ }^{46}$ Acquisition of alterations in the genome of progeny of irradiated cells is described as genomic instability (GI) and it has been accepted as the hallmark of cancer cells and one of the most important factors involved in the development of some cancers. ${ }^{44}$ RIGI was firstly observed in one-cell mouse embryos irradiated with X-rays and with neutrons. ${ }^{47}$ The results suggested that chromosomal aberrations might appear de novo two or three mitoses after initial exposure and also that radiation of a different quality (different LET) induces aberrations at different frequencies.

In the context of RIGI the effect on genome is mediated via the accumulation of genetic changes in the progeny of surviving irradiated cells through many generations. ${ }^{48}$ The capacity to induce genomic instability depends on both dose and quality of radiation, with high LET radiation generally inducing chromosome- and chromatid-type aberrations more effectively. ${ }^{49}$ This effect was observed in murine bone marrow cells irradiated with $0.25 \mathrm{~Gy}$, $0.5 \mathrm{~Gy}$ and $1 \mathrm{~Gy}$ of densely ionizing $\alpha$-radiation. ${ }^{50}$ Colonies arising from irradiated cells exhibited high frequency of non-clonally induced chromatid aberrations consistent with them arising de novo and not directly from irradiation. Early studies using human lymphocytes irradiated in vitro show the ability of low dose X-rays to induce chromosomal aberrations. ${ }^{51}$ Linearity of chromosomal aberration yield was observed above doses of $20 \mathrm{mGy}$ while doses below $20 \mathrm{mGy}$ resulted in yields lower than background. Many researchers have tried to elucidate the mechanisms behind RIGI, especially induced by low dose radiation. Maxwell et al. observed that in HMEC cells irradiated with X-ray doses ranging from 10 to 200 cGy frequency of chromosomal aberrations increased with dose. ${ }^{52}$ In cells irradiated with 50 cGy the frequency of chromosome aberrations increased with time after irradiation up to $72 \mathrm{~h}$. Interestingly, administration of TGF- $\beta$, a growth factor whose activity is induced by radiation, resulted in elimination of cells with chromosome aberrations. The elimination was mediated by induction of p53-dependent apoptosis in genomically unstable cells. Authors also concluded that chromosomal aberrations induced in this experiment are a targeted effect, as induction of chromosomal aberrations above 10 cGy was proportional to dose.

TGF- $\beta$ signaling can be induced in nontransformed cells irradiated with very low doses of radiation. It has been shown that TGF- $\beta$ signaling selectively induces reactive oxygen species (ROS) production in transformed cells leading to their apoptosis. ${ }^{53}$ This signaling pathway could be a part of surveillance network protecting cells from malignant transformation. It is important to note, that radiation induced EMT phenotype can be mediated by TGF- $\beta$, making it a "two-edged sword" in need of further investigation. ${ }^{54}$ Authors suggest that while TGF- $\beta$ might play a role in elimination of irradiated, genomically unstable cells, the chronic exposition to radiation and TGF- $\beta$ signaling can induce EMT in remaining cells. ${ }^{53}$

Dicentric chromosomes are an established marker used to assess IR induced chromosomal aberrations. ${ }^{55}$ Using the measurement of dicentric frequency in human fibroblasts after irradiation, researchers were able to investigate the role of dose-rate effect in induction of chromosome aberrations. ${ }^{13]}$ In cells irradiated with a single X-ray dose the frequency of dicentrics correlated exponentially with doses higher than $0.2 \mathrm{~Gy}$. Irradiation of cells with a single 1 Gy dose of X-rays resulted in similar rise of frequency of dicentrics as irradiation with fractionated $1 \mathrm{~Gy}$ dose (fractionation: 10 x $0.1 \mathrm{~Gy} ; 5$ x $0.2 \mathrm{~Gy} ; 2$ x $0.5 \mathrm{~Gy}$ ) given with intervals of $1 \mathrm{~min}$ between fractions. When intervals between fractions were increased above $5 \mathrm{~min}$, the frequency of dicentric chromosomes was significantly lower, which suggests that the maximum of DNA damage repair, in relation to chromosome dicentrics, is reached after $5 \mathrm{~min}$. These results show that high dose rate irradiation is more harmful to the genome than low dose rate. The measurement of frequency of dicentrics in patients lymphocytes could be utilized in examination of radiosensitivity. Linear dose response of dicentric frequency was observed in human lymphocytes after irradiation with X-ray doses above $20 \mathrm{mGy} .{ }^{51}$ Frequency of dicentrics was also used to evaluate human lymphocytes response to low LET $\gamma$-rays. While for doses above $20 \mathrm{mGy}$ a linear increase in dicentric frequency was observed, authors were not able to detect statistically significant changes in dicentric frequencies below $20 \mathrm{mGy}$ doses, despite counting over 5000 metaphases. ${ }^{56}$ This means that dicentric frequency count might not be a precise enough method for assessment of response to very low doses.

Aneuploidy is a phenotype very often observed in tumors and it arises from incorrect chromosome segregation during mitosis. ${ }^{57}$ Delayed appearance of aneuploid cells induced by low-dose radiation has been observed in vitro in human fibroblasts. ${ }^{58}$ Fibroblasts were irradiated with X-ray doses of 20, 50 or 100 cGy and cultured for five passages. As an end point authors picked assessment of mi- 
cronuclei (MN) formation with special probes for analysis of structural and numerical aberrations ${ }^{59}$, with chromosomes 1 and 4 picked for aneuploidy analysis. Micronuclei are generated in the progeny of irradiated cells as a result of de novo generation of chromosome aberrations. ${ }^{49}$ After X-ray irradiation with doses of 50 and 100 cGy frequencies of centromere-positive and negative MNs increased significantly. Frequency of aneuploidy increased with dose in a dose-dependent manner and after irradiation with 50 and $100 \mathrm{cGy}$ the increase in aneuploidy with time was observed. The data show that after irradiation with low doses, chromosomal aberrations appear de novo up to five population doublings, which as authors suggest, might be connected with variability in the number of centrosomes. ${ }^{60}$

One of the radiation induced phenotypes used to investigate genetic effects of low-dose radiation is loss of heterozygosity (LOH). $\mathrm{LOH}$ is conventionally associated with cancer as a mechanism inactivating tumor suppressor genes, however it is also found in regions of genome responsible for cancer induction. ${ }^{61}$ For research on induction of mutations in vitro, TK6 cells are often used, as this cell line contains heterozygosity at the thymidyne kinase (TK) locus. In one of the experiments irradiation of TK6 cells with 10 cGy X-rays caused a significant increase in hemizygous LOH. ${ }^{61}$ Hemizygous type of $\mathrm{LOH}$ is a result of homologous end joining, a repair pathway observed after irradiation. Umebayashi et al. analyzed induction of $\mathrm{LOH}$ in TK6 cells after irradiation with low-dose, low doserate $\gamma$-irradiation. ${ }^{62}$ Even irradiation with the dose as low as $30 \mathrm{mGy}$ increased the frequency of early mutations in TK gene almost 2-fold. Authors claim that detection of $\mathrm{LOH}$ is an efficient system for estimation of genetic effects induced by low-dose radiation.

\section{Radiation induced bystander effect}

Another non-targeted effect playing a role in carcinogenesis is radiation induced bystander effect (RIBE). This effect together with other non-targeted effects, is often described as most relevant to low-dose radiation ${ }^{63}$ and is mediated through two mechanisms: secretion of soluble factors by irradiated cells ${ }^{64}$ and also by signaling through cell-tocell junctions. ${ }^{65}$ One of the early works in which this effect was described used Chinese hamster ovary $(\mathrm{CHO})$ cells irradiated with low doses of $\alpha$-radiation. ${ }^{66}$ The authors chose very low radiation dose $(0.31 \mathrm{mGy})$, so that less than $1 \%$ of cells were traversed through by the radiation. After irradiation close to $30 \%$ cells exhibited presence of sister chromatid exchanges which suggests, that the genetic damage was induced even in the cells whose nuclei was not traversed through by radiation. Authors speculated that this effect might have been mediated through the production of ROS by the cells which were irradiated directly. The occurrence of RIBE was also confirmed for very low doses of X-ray radiation in human fibroblasts. ${ }^{67}$ After irradiation with doses ranging from 1.2 to $200 \mathrm{mGy}$ the induction of DSBs, measured by ATM phosphorylation, followed a supralinear relationship. While cells were treated with an inhibitor of gap junction intercellular communication, the number of DSBs induced by radiation was smaller than in untreated cells. The largest differences between treated and untreated cells were observed at doses between 1.2 to $5 \mathrm{mGy}$, meaning that RIBE has the most influence on DSB induction at doses up to $10 \mathrm{mGy}$. RIBE has also been shown to induce mutations in bystander cells and the mechanism of these mutations is different than in the cells irradiated directly. ${ }^{68}$ In bystander $\mathrm{CHO}$ cells, the frequency of deletions was higher after using $10 \mathrm{cGy}$ $\alpha$-radiation and after using 0.5 cGy $\alpha$-radiation the frequency of point mutations was higher. Very low doses of $\alpha$-radiation also have the ability to induce ROS production in irradiated cells ${ }^{69}$ and ROS has been shown to induce point mutations ${ }^{70}$ making it the likely mechanism for induction of mutations in bystander cells. However it is not clear whether the effect is mediated through ROS produced by irradiated cells and transferred to unirradiated cells, or the irradiated cells produce factors inducing ROS production in uniradiated cells.

The role of factors secreted by irradiated cells has also been confirmed for low-dose induced RIBE. Seymour and colleagues ${ }^{71}$ irradiated human keratinocytes with doses ranging from 0.01 to 0.5 Gy of $\gamma$-radiation. Then the medium from irradiated cells was collected and transferred to unirradiated cell culture. The results of clonogenic assays measuring clonogenic death of cells show that RIBE mediated by the secreted substances is most predominant in doses below 0.5 Gy. RIBE has also been confirmed to occur in vivo and cause chromosomal instabilities. To first demonstrate this effect in vivo, Watson et al. ${ }^{72}$ transplanted a mixture of irradiated (0.5 Gy, neutrons) and unirradiated bone marrow cells into unirradiated recipient. After transplantation some of the progeny of the unirradiated donor cells showed chromosomal aberrations induced through the bystander effect. 
Evidence has also been presented for oncogenic effect of RIBE in in vivo mouse model, however the effect was observed only after irradiation with $3 \mathrm{~Gy}$ of X-rays. ${ }^{73}$ Currently no research was able to confirm with confidence the oncogenic effect of lowdose RIBE, and even the exact mechanism of RIBE in vivo is not clear. ${ }^{74}$ Presented results suggest that bystander effect plays an important role in induction of mutations after low dose irradiation, making it a potential oncogenic factor.

\section{Conclusions}

Radiation to which humans are exposed comprises mainly of low-dose and low-dose rate radiation from both natural and man-made sources. In recent years the biological effects of low-dose radiation became a point of interest due to the increase in popularity of radiation therapy and diagnostic radiology. Even though many studies point toward a link between carcinogenesis and exposure to radiation, the exact mechanism is still not clear. Induction of genomic instability is suspected to play a major role in malignant transformation after high-dose irradiation, and it might be responsible for carcinogenesis after exposure to lower doses. Latest research suggests that phenomena characteristic for low-dose exposures like HRS and RIBE might be the factors contributing to induction of genomic instability after exposure. Better understanding of these processes is crucial for the proper estimation of low-dose exposure risks for radiation workers, patients and people exposed to high background radiation.

\section{Acknowledgement}

This work was supported by the National Science Centre [grant number: 2015/19/B/NZ7/03811].

\section{References}

1. Ron E. lonizing radiation and cancer risk: evidence from epidemiology. Pediatr Radiol 2002; 32: 232-7. doi: 42-410.1007/s00247-002-0672-0

2. Rowland JH, Kent EE, Forsythe LP, Loge JH, Hjorth L, Glaser A, et al. Cancer survivorship research in Europe and the United States: where have we been, where are we going, and what can we learn from each other? Cancer 2013; 119(Suppl 11): 2094-10810. doi: 1002/cncr.28060

3. Kadhim M, Salomaa S, Wright E, Hildebrandt G, Belyakov OV, Prise KM, et al. Non-targeted effects of ionising radiation--implications for low dose risk. Mutat Res 2013; 752: 84-98. doi: 10.1016/j.mrrev.2012.12.001

4. United Nations Scientific Committee on the Effects of Atomic Radiation. Radiation UNSCotEoA. Sources and effects of ionizing radiation, Annex A. UNSCEAR 2008 report; 2008
5. Veronesi U, Luini A, Del Vecchio M, Greco M, Galimberti V, Merson M, et al. Radiotherapy after breast-preserving surgery in women with localized cancer of the breast. N Engl J Med 1993; 328: 1587-91. doi: 10.1056/ NEJM199306033282202.

6. Radiation UNSCoteoA. Developments since the 2013 UNSCEAR report on the levels and effects of radiation exposure due to the nuclear accident following the great East-Japan earthquake and tsunami. 2016

7. Ciocca M, Pedroli G, Orecchia R, Guido A, Cattani F, Cambria R, et al. Radiation survey around a Liac mobile electron linear accelerator for intraoperative radiation therapy. J Appl Clin Med Phys 2009; 10: 2950.

8. Veronesi U, Gatti G, Luini A, Intra M, Orecchia R, Borgen $P$, et al. Intraoperative radiation therapy for breast cancer: technical notes. Breast J 2003; 9: 106-12.

9. Ward JF. DNA damage produced by ionizing radiation in mammalian cells: identities, mechanisms of formation, and reparability. Prog Nucleic Acid Res Mol Biol 1988; 35: 95-125.

10. Dianov GL, O'Neill P, Goodhead DT. Securing genome stability by orchestrating DNA repair: removal of radiation-induced clustered lesions in DNA. Bioessays 2001; 23: 745-9. doi: 10.1002/bies.1104

11. Lorat Y, Timm S, Jakob B, Taucher-Scholz G, Rube CE. Clustered doublestrand breaks in heterochromatin perturb DNA repair after high linear energy transfer irradiation. Radiother Oncol 2016; 121: 154-61. doi: 10.1016/j. radonc.2016.08.028

12. Takata M, Sasaki MS, Sonoda E, Morrison C, Hashimoto M, Utsumi H, et al. Homologous recombination and non-homologous end-joining pathways of DNA double-strand break repair have overlapping roles in the maintenance of chromosomal integrity in vertebrate cells. EMBO J 1998; 17: 5497-508. doi: 10.1093/emboj/17.18.5497

13. Ojima M, Ito M, Suzuki K, Kai M. Unstable chromosome aberrations do not accumulate in normal human fibroblast after fractionated x-irradiation. PLoS One 2015; 10: e0116645. doi: 10.1371/journal.pone.0116645

14. Hei TK. Response of biological systems to low doses of ionizing radiation. Health Phys 2016; 110: 281. doi: 10. 1097/HP.0000000000000452

15. Lomax ME, Folkes LK, O'Neill P. Biological consequences of radiation-induced DNA damage: relevance to radiotherapy. Clin Oncol 2013; 25: 578-85. doi: 10.1016/j.clon.2013.06.007

16. Jeggo PA. DNA breakage and repair. Adv Genet 1998; 38: 185-218.

17. Short SC, Bourne S, Martindale C, Woodcock M, Jackson SP. DNA damage responses at low radiation doses. Radiat Res 2005; 164: 292-302.

18. Moore S, Stanley FK, Goodarzi AA. The repair of environmentally relevant DNA double strand breaks caused by high linear energy transfer irradiation--no simple task. DNA Repair 2014; 17: 64-73. doi: 10.1016/j. dnarep.2014.01.014

19. Kinner A, Wu W, Staudt C, lliakis G. Gamma-H2AX in recognition and signaling of DNA double-strand breaks in the context of chromatin. Nucleic Acids Res 2008; 36: 5678-94. doi: 10.1093/nar/gkn550

20. Stucki M, Jackson SP. gammaH2AX and MDC1: anchoring the DNA-damageresponse machinery to broken chromosomes. DNA Repair 2006; 5: 534-43. doi: 10.1016/j.dnarep.2006.01.012

21. Tommasino F, Friedrich T, Jakob B, Meyer B, Durante M, Scholz M. Induction and processing of the radiation-induced gamma- $\mathrm{H} 2 \mathrm{AX}$ signal and its link to the underlying pattern of DSB: A combined experimental and modelling study. PLoS One 2015; 10: e0129416. doi: 10.1371/journal.pone.0129416

22. Kegel $P$, Riballo $E$, Kuhne $M$, Jeggo $P A$, Lobrich $M$. X-irradiation of cells on glass slides has a dose doubling impact. DNA Repair 2007; 6: 1692-7. doi: 10.1016/j.dnarep.2007.05.013

23. Rothkamm K, Lobrich M. Evidence for a lack of DNA double-strand break repair in human cells exposed to very low x-ray doses. Proc Natl Acad Sci U SA 2003; 100: 5057-62. doi: 10.1073/pnas.0830918100

24. Osipov AN, Pustovalova M, Grekhova A, Eremin P, Vorobyova N, Pulin A, et al. Low doses of X-rays induce prolonged and ATM-independent persistence of gammaH2AX foci in human gingival mesenchymal stem cells. Oncotarget 2015; 6: 27275-87. doi: 10.18632/oncotarget.4739

25. Liang X, So YH, Cui J, Ma K, Xu X, Zhao Y, et al. The low-dose ionizing radiation stimulates cell proliferation via activation of the MAPK/ERK pathway in rat cultured mesenchymal stem cells. J Radiat Res 2011; 52: 380-6. 
26. Brenner DJ, Hall EJ. Computed tomography - an increasing source of radiation exposure. $N$ Engl J Med 2007; 357: 2277-84. doi: 10.1056/ NEJMra072149

27. Xue L, Yu D, Furusawa Y, Cao J, Okayasu R, Fan S. ATM-dependent hyperradiosensitivity in mammalian cells irradiated by heavy ions. Int I Radia Oncol Biol Phys 2009; 75: 235-43. doi: 10.1016/j.jjrobp.2009.04.088

28. Slonina D, Gasinska A, Biesaga B, Janecka A, Kabat D. An association between low-dose hyper-radiosensitivity and the early G2-phase checkpoin in normal fibroblasts of cancer patients. DNA Repair 2016; 39: 41-5. doi: 10.1016/j.dnarep.2015.12.001

29. Marples B, Collis SJ. Low-dose hyper-radiosensitivity: past, present, and future. Int J Radiat Oncol Biol Phys 2008; 70: 1310-8. doi: 10.1016/j. ijrobp.2007.11.071

30. Marples B, Joiner MC. The response of Chinese hamster V79 cells to low radiation doses: evidence of enhanced sensitivity of the whole cell population. Radiat Res 1993; 133: 41-51.

31. Short SC, Woodcock M, Marples B, Joiner MC. Effects of cell cycle phase on low-dose hyper-radiosensitivity. Int J Radiat Biol 2003; 79: 99-105.

32. Krueger SA, Wilson GD, Piasentin E, Joiner MC, Marples B. The effects of G2-phase enrichment and checkpoint abrogation on low-dose hyper-radiosensitivity. Int J Radiat Oncol Biol Phys 2010; 77: 1509-17. doi: 10.1016/j. ijrobp.2010.01.028

33. Schoenherr D, Krueger SA, Martin L, Marignol L, Wilson GD, Marples B. Determining if low dose hyper-radiosensitivity (HRS) can be exploited to provide a therapeutic advantage: a cell line study in four glioblastoma multiforme (GBM) cell lines. Int J Radiat Biol 2013; 89: 1009-16. doi 10.3109/09553002.2013.825061

34. Sinclair WK. Cyclic X-ray responses in mammalian cells in vitro. Radiat Res 2012; 178: AV112-24.

35. Xu B, Kim ST, Lim DS, Kastan MB. Two molecularly distinct G(2)/M checkpoints are induced by ionizing irradiation. Mol Cell Biol 2002; 22: 1049-59.

36. Marples B, Wouters BG, Joiner MC. An association between the radiationinduced arrest of G2-phase cells and low-dose hyper-radiosensitivity: plausible underlying mechanism? Radiat Res 2003; 160: 38-45

37. Pandita TK, Lieberman HB, Lim DS, Dhar S, Zheng W, Taya Y, et al. lonizing radiation activates the ATM kinase throughout the cell cycle. Oncogene 2000; 19: 1386-91. doi: 10.1038/sj.onc.1203444

38. Lobrich M, Jeggo PA. The impact of a negligent $G 2 / M$ checkpoint on genomic instability and cancer induction. Nat Rev Cancer 2007; 7: 861-9. doi: $10.1038 / \operatorname{nrc2248}$

39. Deckbar D, Jeggo PA, Lobrich M. Understanding the limitations of radiationinduced cell cycle checkpoints. Crit Rev Biochem Mol Biol 2011; 46: 271-83. doi: 10.3109/10409238.2011.575764

40. Deckbar D, Birraux J, Krempler A, Tchouandong L, Beucher A, Walker S, et al. Chromosome breakage after G2 checkpoint release. J Cell Biol 2007; 176: 749-55. doi: $10.1083 / \mathrm{jcb} .200612047$

41. Fernet $M$, Megnin-Chanet $F$, Hall J, Favaudon V. Control of the $G 2 / M$ checkpoints after exposure to low doses of ionising radiation: implications for hyper-radiosensitivity. DNA Repair 2010; 9: 48-57. doi: 10.1016/j. dnarep.2009.10.006

42. Scott D. Chromosomal radiosensitivity, cancer predisposition and response to radiotherapy. Strahlenther Onkol 2000; 176: 229-34.

43. Terzoudi GI, Manola KN, Pantelias GE, Iliakis G. Checkpoint abrogation in G2 compromises repair of chromosomal breaks in ataxia telangiectasia cells. Cancer Res 2005; 65: 11292-6. doi: 10.1158/0008-5472.CAN-05-2148

44. Morgan WF, Day JP, Kaplan MI, McGhee EM, Limoli CL. Genomic instability induced by ionizing radiation. Radiat Res 1996; 146: 247-58.

45. Little JB. Genomic instability and bystander effects: a historical perspective. Oncogene 2003; 22: 6978-87. doi: 10.1038/sj.onc.1206988

46. Kadhim MA, Moore SR, Goodwin EH. Interrelationships amongst radiationinduced genomic instability, bystander effects, and the adaptive response. Mutat Res 2004; 568: 21-32. doi: 10.1016/j.mrfmmm.2004.06.043

47. Weissenborn U, Streffer C. Analysis of structural and numerical chromosomal anomalies at the first, second, and third mitosis after irradiation of one-cell mouse embryos with X-rays or neutrons. Int J Radiat Biol 1988; 54: 381-94.
48. Lorimore SA, Wright EG. Radiation-induced genomic instability and bystander effects: related inflammatory-type responses to radiation-induced stress and injury? A review. Int J Radiat Biol 2003; 79: 15-25.

49. Smith LE, Nagar S, Kim GJ, Morgan WF. Radiation-induced genomic instability: radiation quality and dose response. Health Phys 2003; 85: 23-9.

50. Kadhim MA, Macdonald DA, Goodhead DT, Lorimore SA, Marsden SJ, Wright EG. Transmission of chromosomal instability after plutonium alphaparticle irradiation. Nature 1992; 355: 738-40. doi: 10.1038/355738a0

51. Lloyd DC, Edwards AA, Leonard A, Deknudt GL, Verschaeve L, Natarajan AT, et al. Chromosomal aberrations in human lymphocytes induced in vitro by very low doses of X-rays. Int J Radiat Biol 1992; 61: 335-43.

52. Maxwell CA, Fleisch MC, Costes SV, Erickson AC, Boissiere A, Gupta R, et al. Targeted and nontargeted effects of ionizing radiation that impact genomic instability. Cancer Res 2008; 68: 8304-11. doi: 10.1158/0008-5472. CAN-08-1212

53. Portess DI, Bauer G, Hill MA, O'Neill P. Low-dose irradiation of nontransformed cells stimulates the selective removal of precancerous cells via intercellular induction of apoptosis. Cancer Res 2007; 67: 1246-53. doi: 10.1158/0008-5472.CAN-06-2985

54. Andarawewa KL, Erickson AC, Chou WS, Costes SV, Gascard P, Mott JD, et al. Ionizing radiation predisposes nonmalignant human mammary epithelial cells to undergo transforming growth factor beta induced epithelial to mesenchymal transition. Cancer Res 2007; 67: 8662-70. doi: 10.1158/00085472.CAN-07-1294

55. Bauchinger M, Schmid E, Dresp J. Calculation of the dose-rate dependence of the decentric yield after Co gamma-irradiation of human lymphocytes. Int J Radiat Biol Relat Stud Phys Chem Med 1979; 35: 229-33.

56. Iwasaki T, Takashima Y, Suzuki T, Yoshida MA, Hayata I. The dose response of chromosome aberrations in human lymphocytes induced in vitro by very low-dose gamma rays. Radiat Res 2011; 175: 208-13.

57. Bakhoum SF, Swanton C. Chromosomal instability, aneuploidy, and cancer. Front Oncol 2014; 4: 161. doi: 10.3389/fonc.2014.00161

58. Cho YH, Kim SY, Woo HD, Kim YJ, Ha SW, Chung HW. Delayed numerical chromosome aberrations in human fibroblasts by low dose of radiation. Int J Environ Res Public Health 2015; 12: 15162-72. doi: 10.3390/ijerph121214979

59. Lucas JN, Tenjin T, Straume T, Pinkel D, Moore D, 2nd, Litt M, et al. Rapid human chromosome aberration analysis using fluorescence in situ hybridization. Int J Radiat Biol 1989;56: 35-44.

60. Dahle J, Kvam E. Induction of delayed mutations and chromosomal instability in fibroblasts after UVA-, UVB-, and X-radiation. Cancer Res 2003; 63: 1464-9.

61. Cresti N, Lee J, Rourke E, Televantou D, Jamieson D, Verrill M, et al. Genetic variants in the HER2 gene: Influence on HER2 overexpression and loss of heterozygosity in breast cancer. Eur J Cancer 2016; 55: 27-37. doi: 10.1016/j. ejca.2015.10.066

62. Umebayashi $Y$, Honma M, Suzuki M, Suzuki H, Shimazu T, Ishioka $N$, et al. Mutation induction in cultured human cells after low-dose and low-doserate gamma-ray irradiation: detection by $\mathrm{LOH}$ analysis. J Radiat Res 2007; 48: 7-11.

63. Prise KM, Folkard M, Michael BD. A review of the bystander effect and its implications for low-dose exposure. Radiat Prot Dosimetry 2003; 104: 347-55.

64. Sowa Resat MB, Morgan WF. Radiation-induced genomic instability: a role for secreted soluble factors in communicating the radiation response to non-irradiated cells. J Cell Biochem 2004; 92: 1013-9. doi: 10.1002/ jcb.20149

65. Azzam El, de Toledo SM, Little JB. Oxidative metabolism, gap junctions and the ionizing radiation-induced bystander effect. Oncogene 2003; 22: 70507. doi: 10.1038/sj.onc.1206961

66. Nagasawa $\mathrm{H}$, Little JB. Induction of sister chromatid exchanges by extremely low doses of alpha-particles. Cancer Res 1992; 52: 6394-6.

67. Ojima M, Ban N, Kai M. DNA double-strand breaks induced by very low X-ray doses are largely due to bystander effects. Radiat Res 2008; 170: 365-71. doi: $10.1667 /$ RR1255.1 
68. Huo L, Nagasawa H, Little JB. HPRT mutants induced in bystander cells by very low fluences of alpha particles result primarily from point mutations. Radiat Res 2001; 156: 521-5.

69. Narayanan PK, Goodwin EH, Lehnert BE. Alpha particles initiate biological production of superoxide anions and hydrogen peroxide in human cells. Cancer Res 1997; 57: 3963-71.

70. Oller AR, Thilly WG. Mutational spectra in human B-cells. Spontaneous, oxygen and hydrogen peroxide-induced mutations at the hprt gene. $J \mathrm{Mol}$ Biol 1992; 228: 813-26.

71. Seymour CB, Mothersill C. Relative contribution of bystander and targeted cell killing to the low-dose region of the radiation dose-response curve. Radiat Res 2000; 153: 508-11.

72. Watson GE, Lorimore SA, Macdonald DA, Wright EG. Chromosomal instability in unirradiated cells induced in vivo by a bystander effect of ionizing radiation. Cancer Res 2000; 60: 5608-11.

73. Mancuso M, Pasquali E, Leonardi S, Tanori M, Rebessi S, Di Majo V, et al. Oncogenic bystander radiation effects in Patched heterozygous mouse cerebellum. Proc Natl Acad Sci U S A 2008; 105: 12445-50. doi: 10.1073/ pnas.0804186105

74. Chai Y, Hei TK. Radiation induced bystander effect in vivo. Acta Med Nagasaki 2008; 53: S65-S9. 